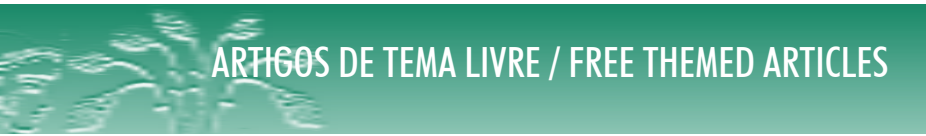

DOI: 10.12957/demetra.2018.31183

\title{
Reflexões para uma abordagem alimentar: sociedade, cultura e fronteiras
}

\section{Reflections for a food approach: society, culture and boundaries}

\author{
Paola Stefanutti ${ }^{1,2}$ \\ Samuel Klauck ${ }^{2}$ \\ Valdir Gregory ${ }^{2}$
1 Instituto Federal do Paraná - Campus Foz do Iguaçu. Foz do Iguaçu, PR, Brasil.
2 Universidade Estadual do Oeste do Paraná, Programa de Pós-Graduação Stricto Sensu Sociedade, Cultura e Fronteiras. Foz do Iguaçu, PR, Brasil.

Este texto foi construído através de discussões provocadas pela disciplina "Sociedade, Cultura e Fronteiras: fundamentos e enfoques interdisciplinares", do Programa de PósGraduação Stricto Sensu - Sociedade, Cultura e Fronteiras da UNIOESTE.

Correspondência / Correspondence Paola Stefanutti

Email: paola.stefanutti@ifpr.edu.br

\section{Resumo}

Os conceitos de sociedade, cultura e fronteiras são polissêmicos, fluidos, flexíveis e permeiam a vida dos indivíduos. A discussão sobre estes três elementos perpassa inúmeras áreas do conhecimento, mas opta-se pela abordagem a partir do fenômeno social da alimentação. A metodologia aplicada é a revisão bibliográfica. Objetiva-se realizar reflexões para uma abordagem alimentar crítica na perspectiva da sociedade, cultura, modernidade e fronteiras, fomentando a articulação entre esses conceitos. As reflexões geraram uma inter-relação entre os conceitos de grupo e coerção social por Émile Durkheim, cultura como mecanismo de controle por Clifford Geertz, modernidade e padronização por Renato Ortiz e a construção de fronteiras por Erneldo Schallenberger, possuindo como discussão de fundo a alimentação. Problematiza-se como a alimentação e os comportamentos alimentares relacionam-se com estes. Pitadas, salpicadas e polvilhadas se encontram na elaboração de um prato intelectual, para ser comido, degustado e apreciado. Espera-se, com este texto, fomentar maiores discussões sobre o fenômeno social da alimentação.

Palavras-chave: Sociologia. Cultura. Modernidade. Comportamento alimentar.

\section{Abstract}

The concepts of society, culture and boundaries are polysemic, fluid, flexible, and permeate the lives of individuals. The discussion on these three elements pervades many areas of knowledge, but 
we chose the approach from the social phenomenon of food. The bibliographical review methodology was applied. The objective is to carry out reflections for a critical food approach from the perspective of society, culture, modernity and boundaries, fostering the articulation between these concepts. The reflections generated an interrelationship between group concepts and social coercion by Émile Durkheim; culture as a mechanism of control by Clifford Geertz; modernity and standardization by Renato Ortiz; and the construction of boundaries by Erneldo Schallenberger. There has been problematization of how feeding and eating behaviors relate to these. Speckled and sprinkled are present in the elaboration of an intellectual dish, to be eaten, tasted and appreciated. With this text, it is expected to foster further discussions on the social phenomenon of food.

Keywords: Sociology. Culture. Modernity. Food behavior.

\section{Introdução}

"Sociedade", "cultura" e "fronteiras" são palavras separadas cujos conceitos são polissêmicos, mas que podem ser relacionados e interligados. "Sociedade, cultura e fronteiras" também dá nome a um programa de Pós-Graduação Stricto Sensu da Universidade Estadual do Oeste do Paraná (UNIOESTE). No entanto, mais do que uma denominação, estes três elementos representam as complexas articulações e diálogos das pesquisas desenvolvidas neste Programa, que se baseiam em fenômenos ou fatos sociais provocados por seres humanos e grupos sociais.

O fenômeno social está balizado no local e no tempo em que se está. Assim, esta produção textual e intelectual só foi possível, com esta maneira de escrita, conteúdo e perspectiva, porque foi desenvolvida em determinado período em 2016/2017, nesta academia, na cidade de Foz do Iguaçu, com esses professores, com essas leituras, embasadas no pensamento e paradigma ocidental, com alunos que agregaram na participação dos debates, com a formação prévia de uma das autoras em Gastronomia, e dos demais autores em História.

Decerto, deveríamos ter iniciado com o texto proposto realizando as discussões que se esperavam do artigo. Mas acreditamos que o meio, o indivíduo, as memórias, os conhecimentos anteriores, o contexto social, interferem na maneira como interpretamos os dados, os conteúdos e as representações. Assim, buscamos contextualizar o leitor a respeito das vivências acadêmicoprofissionais, e do local e momento em que nos encontramos, enfatizando que estas questões refletem nossa percepção de mundo e na nossa perspectiva frente aos fenômenos sociais. Os 
fenômenos seriam diferentes se estivéssemos produzindo em outro lugar da África, Ásia ou Europa. Nós seríamos diferentes.

A discussão sobre estes três conceitos perpassa inúmeras áreas do conhecimento, mas opta-se pela abordagem a partir de um fenômeno social que possui papel central no cotidiano e pode ser considerado inerente a qualquer ser humano - seja pela falta ou pela presença - a alimentação. Ademais, a alimentação é o chão que piso, ${ }^{a 1}$ tendo uma expressiva tendência a pesquisar sobre o tema, pois compreendemos que um trabalho intelectual seja também um trabalho pessoal.

Neste trabalho, faz-se uma correlação da alimentação com autores de áreas paralelas, mas que aqui, nestas folhas se conversam, aplicando-se a metodologia da revisão bibliográfica. Objetiva-se realizar reflexões para uma abordagem alimentar crítica na perspectiva da sociedade, cultura, modernidade e fronteiras, fomentando a articulação entre esses conceitos. Problematiza-se como a alimentação relaciona-se com essas concepções. As reflexões geraram uma inter-relação entre os conceitos de grupo e coerção social por Émile Durkheim, cultura como mecanismo de controle por Clifford Geertz, modernidade e padronização por Renato Ortiz, e a construção de fronteiras por Erneldo Schallenberger, possuindo como discussão de fundo a alimentação. Estas reflexões são a contribuição deste trabalho.

Pitadas, salpicadas e polvilhadas se encontram na elaboração de um prato intelectual, para ser comido, degustado e apreciado. Há temperos de diversas origens, é a sociedade, é a cultura, é a modernidade, é a fronteira.

\section{Pitadas de sociologia e cultura a partir de Durkheim e Geertz}

Ao discutir a alimentação como um fenômeno social que surge e se constrói no âmbito da sociedade, torna-se imprescindível uma problematização anterior em relação à compreensão da própria sociedade, dialogando com autores clássicos e verificando como pensavam e concebiam a sociedade.

Compreender a realidade, e a sociedade que nos cerca, faz parte do trabalho do pesquisador; de um modo ou de outro, buscamos conceber determinada realidade social. Para essa discussão, fazem-se reflexões a partir de Anthony Giddens, ${ }^{2}$ sociólogo britânico, em seu livro Capitalismo $e$ Moderna Teoria Social. Nessa obra Giddens traz uma exposição e um estudo comparativo das três maiores raízes do pensamento sociológico ocidental, com seus respectivos teóricos: Karl Marx, Émile Durkheim e Max Weber. Sendo estas as bases do pensamento ocidental da forma de compreender o mundo, são teorias explicativas da sociedade, maneiras de enxergar e trabalhar a realidade, um

a Fazendo alusão ao capítulo "O chão que pisamos”. Flusser, V. Pós-história: vinte instantâneos e um modo de usar. São Paulo: Duas Cidades, 1983. 
por meio da luta de classes, outro pela coerção social e outro pela fenomenologia. O econômico, o social e o fenomenológico. Marx, Durkheim e Weber. Como o autor descreve:

As obras de Marx constituem, como é óbvio, a principal fonte das várias formas de neomarxismo contemporâneo; as obras de Durkheim influenciaram de modo determinante o $<<$ funcionalismo estrutural $>>$ dos nossos dias; e pelo menos, algumas das variantes modernas da fenomenologia derivam directa ou indirectamente das obras de Max Weber (Giddens, 2005, p.12).

Mesmo inconscientemente, nossa visão de mundo é influenciada por um desses pensadores. Esses conceitos são fluidos, perpassam a academia e transbordam a fronteira dos muros da universidade.

Apesar de Marx ter contribuído para a compreensão da sociedade a partir do mercado e do capital, e de Weber difundir o importante conceito da teia de significados, é em Durkheim que encontramos maior respaldo teórico em relação ao modo de interpretar a sociedade. O sociólogo é pioneiro em trazer à tona discussões sobre a organização da sociedade através da moral coletiva e coerção social.

Em comparação aos demais, Durkheim foi o que mais se manteve afastado: "[...] a um nível pessoal, dos grandes acontecimentos políticos do seu tempo: as suas obras são quase todas de caráter acadêmico, e, portanto, muito menos dispersas - e menos propagandísticas - do que as de Marx ou Weber" (Giddens, 2005, p.109).

A maior contribuição de Durkheim foi demonstrar que: "[...] as regras e as acções morais podem ser cientificamente estudadas, na sua qualidade de propriedades da organização social. Durkheim define neste ponto um preceito que havia de vir a ser um dos princípios orientadores de toda a sua obra" (Giddens, 2005, p.114). Portanto, a sociedade passa a poder ser compreendida e analisada enquanto algo palpável. As ações são sociais e as respostas também o são. "As regras morais surgem no seio da sociedade, ligando-se integralmente às condições de vida social vigentes em determinado tempo e local" (Giddens, 2005, p.118). Para Durkheim, a coerção social, gerada através da exterioridade e constrangimento, e do reforço da moral coletiva, é a lógica da moral social para compreender a sociedade. A negociação inerente entre o Eu e o Outro.

Dois de seus estudos mais difundidos são sobre o comportamento religioso e o suicídio. Porém, pode-se estender essas discussões para outros fenômenos sociais, como a alimentação. Esta não está deslocada, não está na natureza - está na sociedade. Qualquer comportamento social pode e deve ser analisado, porque ele é socialmente construído.

As ideias sobre coesão e moral social de Durkheim encontram continuidade nos estudos sobre cultura, do antropólogo estadunidense Clifford James Geertz (1989), ${ }^{3} \mathrm{em}$ seu livro A Interpretação das Culturas. A síntese de Geertz possui duas grandes afirmações; a primeira é de que a cultura: 
[...] é melhor vista não como complexos de padrões concretos de comportamento - costumes, usos, tradições, feixes de hábitos -, como tem sido o caso até agora, mas como um conjunto de mecanismos de controle - planos, receitas, regras, instruções (o que os engenheiros de computação chamam “programas") - para governar o comportamento (Geertz, 1989, p. 32, grifo nosso).

Portanto, Geertz ${ }^{3}$ defende a ideia da cultura como um conjunto de mecanismos de controle para governar o comportamento, impondo uma visão de mundo. Pode-se afirmar, segundo o autor, que nossas ideias, valores, atos, emoções, e até nosso sistema nervoso, são produtos culturais, manufaturados, produzidos, construídos a partir de tendências e habilidades inatas (Geertz, 1989, p.36). No final, fomos e somos produzidos. Neste jogo social, somos artefatos culturais. Sendo assim, a cultura pode ser compreendida como um fenômeno social construído.

A segunda é que o homem: "[...] é precisamente o animal mais desesperadamente dependente de tais mecanismos de controle, extragenéticos, fora da pele, de tais programas culturais para ordenar seu comportamento" (Geertz, 1989, p.32-33). Portanto, a cultura é um mecanismo de controle do qual o indivíduo carece e depende.

Diante de um termo tão polissêmico, Geertz ${ }^{3}$ diz que: "O ecletismo é uma autofrustração, não porque haja somente uma direção a percorrer com proveito, mas porque há muitas: é necessário escolher" (Geertz, 1989, p.4). E segundo sua escolha pessoal, o conceito de cultura é essencialmente semiótico. Concordando com Max Weber, que o homem é um ser amarrado a teias de significados tecidas por ele mesmo, Geertz assume a cultura como sendo essas teias e suas análises, não como uma ciência experimental, mas como uma ciência interpretativa, à procura do significado (Geertz, 1989, p.4). Assim, a cultura não é a coisa em si, mas é o significado empregado nesta coisa. A cultura não são os artefatos, mas seus significados e representações. A cultura não é o efeito, mas a causa. A cultura não é a comida em si, mas suas representações simbólicas.

Sobre a sociedade, Giddens $s^{2}$ (2005, p.69-70) afirma que: "Segundo Marx, o progresso da sociedade é a resultante da interacção produtiva contínua que se estabelece entre os homens e a natureza". E o autor continua: "A atividade produtiva está pois na base de toda a sociedade, e isto num sentido tanto histórico como analítico". Porém, "Os seres humanos não produzem individualmente, mas como membros de uma determinada forma de sociedade [...]" - sendo que, nesta produção, os homens atuam não apenas sobre a natureza, mas sobre outros homens.

É fato que a sociedade é regida pela lógica do mercado, conforme defende Marx, porém, como Giddens² (2005, p.114) ressalta o pensamento de Durkheim: "Se não existissem as normas sociais que permitem contrair contratos, reinaria no mundo econômico $<<u$ um caos incoerente $>>$. As regras que controlam a vida econômica não podem ser explicadas em termos puramente econômicos". Portanto, explicar o econômico, apenas pelo econômico, é determinismo e reducionismo. 
Se fôssemos levar essa discussão para a alimentação, seria como afirmar que o fator econômico é o aspecto que influencia nos comportamentos alimentares. Seria como diminuir ou abafar uma série de outros elementos, como: religiosos, físicos, psicológicos, políticos, midiáticos, sociológicos, culturais, científicos e até mesmo a disponibilidade de tempo e do produto. Portanto, o econômico não é determinante, os fatores sociológicos são fluídos.

Nessa questão ainda permeia a relação entre a escolha do alimento e o indivíduo. Em algumas situações e teorias, parece que o indivíduo age independentemente da realidade a sua volta e consome o que tem desejo, sem nenhuma relação com o social. Durkheim rebate a ideia do individualismo, criticando o conceito de que cada um é cada um, e que a sociedade não nos determina enquanto sujeitos:

Os ideais e os sentimentos que constituem a herança cultural dos membros de uma sociedade são $<<$ impessoais $>>$, isto é, desenvolvem-se socialmente, e não são o fruto nem a propriedade de indivíduos específicos. Demonstra-no-lo o exemplo da linguagem: <<cada um de nós fala numa linguagem que não criou $>>$ (Giddens, 2005, p.112). ${ }^{2}$

O homem enquanto indivíduo não pode ser levado para explicar uma sociedade. A sociedade, o que está a sua volta, o influencia. Portanto, o indivíduo não existe por si só; ele existe como ele é, pois está na sociedade. Parafraseando o autor, cada indivíduo come uma comida que não criou.

Nesta discussão pode-se problematizar as escolhas alimentares, ou ainda, quando um ingrediente se torna uma opção de consumo. O antropólogo Roberto DaMatta $(1986)^{4}$ diz que: "Temos então alimento e temos comida. Comida não é apenas uma substância alimentar, mas é também um modo, um estilo e um jeito de alimentar-se. E o jeito de comer define não só aquilo que é ingerido como também aquele que ingere" (DaMatta, 1986, p.55-56, grifo nosso). O alimento então se torna a peça bruta; e a comida, seu refinamento. O selvagem e o doméstico, o natural e o cultural, o cru e o cozido, o alimento e a comida. Lembra-se aqui da concepção do cru e do cozido do antropólogo francês Lévi-Strauss.

Nesse sentido, pode-se refletir que nem tudo o que alimenta é bom ou socialmente aceitável. Do mesmo modo, nem tudo o que é alimento é comida. Para essa discussão, não poderia faltar outro antropólogo francês dedicado ao estudo da alimentação, Claude Fischler, ${ }^{5}$ ao dizer, sucintamente, que: "[...] tudo o que é biologicamente comestível não é culturalmente comestível" (Fischler, 1995, p.33, tradução nossa). Ou seja, nem tudo o que é biologicamente comestível, o é culturalmente. É a diferença entre o alimento e a comida. A carne bovina pode ser comida, comestível na cultura gaúcha, mas não o é na cultura indiana, por uma questão religiosa. Assim como alguns insetos são comida, comestíveis em alguns países asiáticos, ou tribos indígenas brasileiras, mas não o são em outras culturas. Mesmo assim, porém, tanto a carne bovina como os insetos continuam sendo alimento. 
Nesta perspectiva pode-se questionar que, na sociedade brasileira, quando se refere à proteína animal convencionalmente, está se referindo à carne bovina, suína ou de aves, e não carne de cachorro ou gato. Não é o animal A e B que está em questão, mas como essa determinada sociedade faz a leitura sobre o mesmo. Qual é o significado que ele carrega, além de ser o que ele é? Animal para consumo alimentar, animal para consumo emocional. Portanto, alimento e comida se diferenciam no social, e não no individual, conforme aponta Durkheim.

Diante destas colocações, questiona-se sobre a cultura alimentar. Tema de inúmeros artigos, livros e textos, a ligação entre alimentação e cultura é algo intrínseco. A todo momento, uma palavra se vincula a outra, parecem conceitos inatos. Compreende-se, porém, como Geertz aponta, que mais do que uma visão romantizada de cultura, como algo sagrado, concreto e fixo, a cultura é construída, é fluida, é mecanismo de controle, não sendo algo individual.

Os comensais comem cultura, pois comer não é um ato neutro, assim como a comida também não o é, uma vez que a escolha dos comensais vem carregada de significados e de simbologias culturais. Então cabe dizer que a comida é culturalizada, afinal comemos comida, comemos cultura, comemos momentos, comemos pessoas e comemos memórias (Stefanutti, 2015). ${ }^{6}$

Por mais que possa haver escolhas individuais, a cultura alimentar está baseada em uma coesão social, como lembra Durkheim, que possui sua lógica de mercado segundo Marx e que está emaranhada em teias de significado, como nos relembra Weber. A comida não é só o ingrediente em si. É símbolo, é significado, é representação de determinada sociedade que se identifica como tal.

Para Geertz, ${ }^{3}$ a cultura é pública, é social, pois seu significado também o é. Se não tivesse uma compreensão do significado, não haveria cultura. Não faria sentido. A comunicação não seria efetivada. Não haveria transmissão de significado através de objeto, gesto, música, comida, entre outros. Por exemplo: "Nossa capacidade de falar é inata certamente, nossa capacidade de falar inglês, porém, é sem dúvida cultural” (Geertz, 1989, p.36). Nossa capacidade de comer é inata, porém nossa capacidade de comer arroz e feijão é cultural. O autor ainda diz que: "O homem pode ser definido pelo elo entre como as habilidades inatas é transformada em comportamento real" (Geertz, 1989, p.37-38).

Apesar das contribuições de Durkheim, é necessário criticá-lo ao apontar a análise da sociedade como estruturalista, como se a mesma lógica fosse aplicada a todos os espaços e tempo, sem levar em consideração os contextos, derivando uma compreensão da noção de sociedade de forma fechada. Durkheim trata os fatos sociais como coisas, mas como diz o sociólogo austríaco Michael Pollak, ${ }^{7}$ não se trata de abordar fatos sociais como coisas, mas de compreender como se tornam coisas, por quem são validados como tal, e como se mantêm como coisas.

Portanto, o pesquisador deve entender o contexto para explicar o fenômeno, relação de causa e efeito. Não é o efeito, o ato em si que deve ser analisado, mas as causas, as motivações, os 
porquês, as entrelinhas. Olhando para o objeto de Durkheim, o suicídio, o que interessa é como o suicídio é possível, como ele ocorre, o que leva a ocorrer este fenômeno social. Lembramos, do historiador italiano Carlo Ginzburg, ${ }^{8}$ a busca nas entrelinhas, nos não-ditos, nas beiradas, no que não está aparente, a leitura por trás das coisas. Neste sentido, Ginzburg contrapõe Durkheim com o método indiciário.

Trazendo essa discussão para a alimentação, não é analisar apenas o arroz e o feijão, mas verificar como foram introduzidos no território nacional e na mesa dos que aqui viviam, como eles se tornaram escolhas, como se transformaram em comida símbolo da cozinha brasileira e por quem eles são considerados como tal. Olhar além do ingrediente, com suas propriedades nutricionais e funcionais e características organolépticas, mas contemplá-lo como um elemento cultural, social, econômico, político, somado às representações e simbologias que ele pode assumir ao longo de um período em determinado espaço.

Com reflexões sobre sociedade na perspectiva de Durkheim e sobre cultura na perspectiva de Geertz, introduz-se o próximo subitem deste artigo, sobre a modernidade e a padronização alimentar a partir de Renato Ortiz.

\section{Salpicadas de modernidade e a padronização alimentar a partir de Ortiz}

Alguns fatos históricos marcaram não só o tempo de quem os vivenciou, mas deixaram marcas irreversíveis na história da humanidade, porém nenhum deles é tão representativo quanto a Revolução Industrial. Fábrica, lã, ovelha, êxodo rural, ingresso de mão-de-obra, força de trabalho, mais-valia, desigualdade social, padronização, homogeneização, capitalismo, modernidade. Mas afinal, como esta Revolução e a consequente modernidade nos afetam?

A padronização e a homogeneização de costumes, comportamentos, valores, línguas, vestimentas e comidas são evidências dessa intervenção, possível através na coesão social de Durkheim, anteriormente discutida.

Fazem-se reflexões a partir do sociólogo brasileiro Renato Ortiz, ${ }^{9}$ que discute sobre a padronização alimentar através do que propôs Lucien Febvre, que pretendia determinar a origem e a difusão das gorduras básicas (banha, manteiga e azeite) no território francês.

Problematizando e consentindo com os antropólogos espanhóis da área da alimentação, Contreras \& Gracia, ${ }^{10}$ afirma-se que as cozinhas refletem as sociedades. "Cada grupo social possui um quadro de referências que guia a escolha de seus alimentos. Algumas dessas referências são compartilhadas com outros grupos, outras são exclusivas" (Contreras; Gracia, 2011, p.139). Porém, essa afirmação não significa que os comportamentos alimentares se mantiveram estáticos e não sofreram alternações em suas sociedades e seus respectivos territórios. 
Se História, Antropologia e Geografia convergem na consolidação da territorialidade das culturas, como afirma Ortiz, ${ }^{9}$ o Turismo e a Gastronomia também cumprem o mesmo papel de consolidar culturas em determinados territórios. Porém: "O advento das técnicas de conservação, o barateamento do transporte, a invenção da comida industrial transformaram radicalmente este quadro. Por isso alguns estudiosos começam a falar de internacionalização dos comportamentos alimentares" (Ortiz, 2003, p. 79). O homem domina a natureza, e nessa intenção de dominar, ele acaba sendo dominado.

Segundo o historiador italiano Massimo Montanari, ${ }^{11}$ (2008, p. 36), a ciência e a técnica sempre quiseram controlar o tempo em duas principais linhas de ação: prolongá-lo com a diversificação das espécies e pará-lo com as técnicas de conservação dos alimentos. Montanari ${ }^{11}$ (2008, p. 38) ainda cita o sociólogo Girolamo Sineri, que diz: "A conserva é ansiedade em estado puro". Ressalta-se que o acesso à eletricidade, nas zonas urbanas e rurais, é uma realidade relativamente nova no contexto da história da humanidade. A conservação pode ser concebida como um princípio da modernidade, pois é necessário a acumulação de hoje para a sobrevivência do amanhã. Uma lógica contrária ao pensamento dos guaranis e de alguns pescadores, por exemplo.

Embutidos, salames, linguiças, compotas de verduras e frutas são processos de conservação de alimentos que a humanidade desenvolveu para aumentar o tempo de vida dos produtos. Em Luís da Câmara Cascudo ${ }^{12}$ (2004, p. 152), autor brasileiro de História da Alimentação no Brasil, encontram-se referências sobre a conservação das carnes em gordura, especialmente da banha de porco, toucinho derretido, da carne suína, em Portugal, em períodos anteriores. Até a própria cocção é um método de conservação, juntamente com o sal. As técnicas de conservação de alimentos eram sinal de disponibilidade de alimento em períodos de abundância e/ou escassez.

Além da conservação de alimentos, $\operatorname{Ortiz}^{9}$ (2003, p.81) afirma que dois movimentos evidenciam o processo da mundialização: a diversificação dos produtos e a passagem da cozinha tradicional para uma cozinha industrial. Sobre a diversificação dos produtos, pode-se dizer que há um paradoxo, pois ao mesmo tempo que houve a diversificação, ocorreu uma diminuição drástica da biodiversidade. Exemplo disso são as batatas no Peru. Segundo o Centro Internacional de la Papa (CIP), ${ }^{\text {b13 }}$ com sede em Lima, capital do Peru, existem mais de 4.000 variedades comestíveis de batata, encontradas principalmente nos Andes da América do Sul, sendo que este Centro abriga as sementes de todas essas espécies. Diante desse cenário, questiona-se: quantas espécies de batatas estão disponíveis no mercado no nível mundial? Conseguiríamos listar dez espécies? Para reflexão. Diminuem-se as variedades e aumenta-se a distribuição, é a lógica do mercado.

A cozinha tradicional e a cozinha industrial vivem em uma intensa troca de ingredientes e técnicas, de um lado os pratos introduzidos adaptam-se ao paladar local, sendo sincretizados de

b Ver mais em: <http://cipotato.org/potato/>. 
acordo com as normas culinárias vigentes. E de outro lado, pratos tradicionais são incorporados à cozinha industrial, porém perdem sua singularidade e identidade ${ }^{9}$ (Ortiz, 2003, p. 77-78). É complexa a nomenclatura de cozinha "tradicional" utilizada por Ortiz, mas é evidente a tendência para a padronização alimentar.

[...] cada vez mais diminui o consumo de legumes e de frutas secas, mas aumenta o de conservas, geleias, biscoitos, doces industriais, comidas dietéticas, pratos congelados, etc. As conquistas tecnológicas "libertam" os alimentos do meio ambiente, do solo que os prendia às regiões (Ortiz, 2003, p. 84).

Nessa internacionalização dos comportamentos alimentares, os alimentos desapegam-se do seu território para serem mundialmente distribuídos. Assim, como uma das consequências da modernidade, pode-se verificar o rompimento do vínculo entre lugar e alimento. A comida em escala industrial não contém relação territorial, e se o possui é essencializada, como se todo norte-americano só consumisse hambúrguer; todo mexicano, tacos e nachos; todo japonês, sushi e sashimi; e todo chinês, yakisoba. Ideias essencializadas e interiorizadas através das grandes cadeias de fast food, assim como afirma $\operatorname{Ortiz}^{9}$ (2003, p. 82): "Interessa menos no caso McDonald's sua americanidade, do que o fato de ele exprimir um novo padrão alimentar, o fast-food". Não é só a comida, o ingrediente, mas a padronização da produção, do atendimento, e por que não dizer do próprio cliente. Assim, a discussão essencializada sobre a origem e difusão das gorduras no território francês perde sentido, assim como outras afirmações alimentares essencializadas.

A padronização alimentar não ocorreu apenas nos comportamentos, práticas e hábitos alimentares, mas também nos modos à mesa, na "civilidade" à mesa, uma distinção de quem tem e quem não tem. A mesa é fronteira, ela separa os diferentes e une os iguais. A mesa não é democrática. O saber se portar à mesa é símbolo de cultura, de status, de diferenciação, de modernidade, de civilidade. Como pode ser visto no livro O processo civilizador: 1. Uma história dos costumes, do sociólogo alemão Norbert Elias, ${ }^{14}$ que relata as normas de conduta à mesa, dos comportamentos à mesa, sendo este um processo de civilidade e de bons costumes.

A modernidade padronizou comportamentos alimentares. Reinventa-se essa modernidade através dos discursos alimentares. Se o fast food, a comida rápida, a comida pronta, foram os primeiros indícios dessa padronização alimentar, a obesidade foi sem dúvida, uma de suas consequências. O que desencadeou um discurso da comida natural, saudável, chegando até à "remedialização" da comida, ou seja, o alimento virou remédio.

Nossa sociedade é dirigida pela lógica do mercado e a coerção social pode ser verificada através dos discursos alimentares se determinado produto é benéfico ou não à saúde. Um dia aprendemos que a banha de porco faz mal, outro dia não podemos consumir manteiga, meses depois é o óleo de soja nosso maior inimigo, o azeite não pode ser aquecido, e sem ver, vinte anos depois a banha 
de porco é a nova aliada no combate às doenças cardiovasculares. Portanto, capitalismo, coesão social, cultura, significados, modernidade e padronização estão entrelaçados em um emaranhado que influencia os comportamentos alimentares.

A seguir, discussões sobre reflexões culturais e fronteiriças.

\section{Polvilhadas de Reflexões Culturais e Fronteiriças}

A sociedade é organizada a partir das fronteiras, e assim como ela, as fronteiras são fluidas. As fronteiras não são naturais; são símbolos das relações sociais e suas coerções e coesões. Portanto, não é possível compreender as fronteiras sociais sem contextualizar a noção de tempo e espaço.

Se para Giddens² (2005, p.69), "cada um dos indivíduos, no seu dia-a-dia, recria e reproduz a sociedade a todo o momento; esse fenômeno está na origem tanto da estabilidade da organização social como das infinitas modificações dessa mesma organização". Pode-se dialogar com José Lindomar Coelho Albuquerque, ${ }^{15} \mathrm{em}$ seu texto Fronteiras: entre os caminhos da observação e os labirintos da interpretação, que trata como as pessoas em sua cotidianidade fazem a fronteira, como o brasileiro, o paraguaio, o brasiguaio, fazem a fronteira entre Brasil e Paraguai. Como o motoboy, o pescador, a comida, fazem a fronteira? A fronteira é o humano, isto é, ela é a ação do humano na própria formação das fronteiras.

Concorda-se nesta questão com Geertz, ${ }^{3}$ que afirma: “[...] você quer compreender o que é a ciência, você pode olhar, em primeiro lugar, não para as suas teorias ou as suas descobertas, e certamente não para o que seus apologistas dizem sobre ela; você deve ver o que os praticantes da ciência fazem" (Geertz, 1989, p.4). Compreender por que eles fazem o que fazem, o olhar além do que está aos olhos. Se o objetivo é compreender a fronteira, deve-se olhar, como Albuquerque, para os que fazem, vivem e praticam a fronteira.

E se o objetivo compreender os comportamentos alimentares, deve-se olhar para os praticantes da alimentação, para o indivíduo e suas práticas alimentares. Mas além disso, olhar além da coisa, não olhar o comer com as mãos ou os talheres, mas entender por que cada um come do seu jeito. Interpretar o que está sendo analisado e ir além, em uma leitura mais densa, mais profunda. Geertz ainda afirma que o comportamento humano é visto e pode ser compreendido como ação simbólica.

A ideia de fronteiras polissêmicas e construídas por quem dialoga com as fronteiras pode ser aplicada a todas as áreas do conhecimento e aos objetos de estudo. A literatura pode discutir fronteiras, pois ela possui fronteiras. Assim como a comida também pode. O saber comer versus o não saber comer; as cozinhas clássicas versus as cozinhas regionais; a comida erudita versus a comida popular; a comida típica versus a comida construída. 
Além do mais, é necessário um olhar para nossos próprios sentidos físicos que captam nossa experiência sensorial no mundo, visão, paladar, tato, olfato, audição, para compreender como as pessoas operam seus sentidos para agir no mundo e com o outro ${ }^{15}$ (Albuquerque, 2014, p.65).

O historiador Erneldo Schallenberger, ${ }^{16}$ no ensaio Ruptura histórica e (des)continuidades culturais na fronteira: os desafios do pesquisador, contribui com as discussões sobre fronteiras, descrevendo o processo das ações de aproximação e estranhamento durante a colonização da América, focando as regiões de fronteiras, e como as fontes cartográficas foram essenciais nesse processo. A geografia evidencia fronteiras, e os documentos também. O historiador faz uma retrospectiva da colonização e demonstra como políticas do outro lado do Atlântico, entre Portugal e Espanha, influenciavam diretamente na Bacia do Prata. Guaranis, jesuítas, metrópole, colônia, tratados, Estados-Nação, colonos, imigrantes e Itaipu, se veem entrelaçados em uma trama, de vários lados, no estabelecimento de fronteiras nacionais e suas significações. As fronteiras vão sendo construídas. São fenômenos sociais, advêm dessas interações.

$\mathrm{O}$ autor salienta que os sujeitos sociais que constroem a fronteira, o fazem a partir do local de onde vieram e do mundo de significados, símbolos e representações que já tinham anteriormente. Assim, as relações nas fronteiras acabam produzindo diferenciações. E "no encontro de povos com mundos de significação e representação diferentes, o espaço passa a se configurar como um palco simbólico onde se travam relações de poder" (Schallenberger, 2014, p.215). Nesse palco emaranhado pelas relações de poder estão os estabelecimentos de conceitos, ideias, identidades, culturas fixas, sendo a determinação dos limites entre o Eu e o Outro expressa pelos essencialismos.

Apesar de discutir sobre identidades essencializadas, a socióloga Kathryn Woodward ${ }^{17}$ pode contribuir com essa discussão, pois, segundo a autora, o "essencialismo" pode ter um respaldo biológico e natural, ou histórico e cultural. Independentemente da raiz, no entanto, ele continua sendo essencialista ao ter uma concepção de identidade fixa, única e estática. Para Woodward, ${ }^{17}$ uma definição não-essencialista levaria em conta, além das próprias definições (essencialistas), a explicação de como as identidades foram formadas, os processos e negociações envolvidos, e até como essas identidades mudaram ao longo do tempo, questionando-se, se de fato, as identidades são fixas.

Faz parte do cotidiano essencializar as fronteiras. A essencialização homogeneíza todos. Ela nega a diversidade. A fronteira essencializada é resultado dos Estados-nação. A ideia de fronteira nasce a partir da construção dos Estados-nação. Como dizer que a chipa é paraguaia sem essencializar a fronteira e a própria chipa? Seguindo o exemplo de Schallenberger, a resposta seria contextualizar a chipa: que é feita a partir do alimento básico, o milho; que o milho é encontrado dos Estados Unidos à Patagônia; que tem raízes indígenas; que possui técnicas indígenas; que contém influência espanhola; e que o território onde havia o preparo e o consumo da chipa hoje pertence ao Paraguai, local onde ainda é consumido. Não é reduzir o fenômeno, mas reconhecer 
que o Paraguai existe, que ele produz um alimento, carregado de técnicas, e que esta preparação alimentar é capaz de representar os seus.

\section{Considerações finais}

Os conceitos de "sociedade", "cultura" e "fronteiras" são polissêmicos, fluidos, flexíveis, permeiam a vida dos indivíduos. Estão na nossa rotina, no nosso cotidiano. Como o conceito de fronteira transcende a questão espacial e de determinação geográfica, mesmo quem não se considera em uma região de fronteira, a vivência em uma esfera social, cultural, política, econômica, alimentar. Da série de fatos sociais que poderiam ser escolhidos para discutir os três elementos, optamos por um fato concreto: a alimentação.

Através das ideias de Durkheim, pode-se estabelecer paralelos em relação aos comportamentos alimentares, pois os mesmos são construídos a partir da coesão e moral social. E não devem ter uma perspectiva reducionista ao discutir tais comportamentos no âmbito individual, pois são construídos socialmente.

Essas ideias concordam com as de Geertz: a cultura é um mecanismo de controle, construído socialmente, do qual o indivíduo carece e depende. E não é a coisa em si, o artefato, o objeto, a comida, mas seus significados e representações, como pode ser visto através das discussões sobre o arroz e feijão, a carne bovina, os insetos e as proteínas animais no território nacional. Opõem-se ainda ao conceito de Durkheim, no que se refere a analisar o fenômeno a partir de seus efeitos.

A modernidade homogeneíza, neutraliza os diferentes, tende à padronização. Padroniza costumes, comportamentos e comidas. As técnicas de conservação, os meios de transporte mais acessíveis financeiramente, o constante desenvolvimento tecnológico da comida industrial, a diversificação das espécies e os discursos alimentares deram subsídios para a padronização, também denominada de "internacionalização" dos comportamentos alimentares. A comida se desconecta do território, ela não está mais ligada a ele e aos seus, ela é mundial. Ela é de todos, e não é de ninguém.

A ideia de fronteiras polissêmicas e construídas por quem dialoga com as fronteiras pode ser aplicada a todas as áreas do conhecimento e aos objetos de estudo, sendo este o principal propósito deste subitem. Os sujeitos sociais que constroem a fronteira, o fazem a partir do local de onde vieram e do mundo de significados, símbolos e representações que já tinham anteriormente. Faz parte do cotidiano essencializar as fronteiras. A procura pela origem de determinado prato ou ingrediente é um indício do essencializar a fronteira e o próprio prato. Neste caso, com a discussão da chipa. Compreender um prato, um ingrediente, uma comida sem essencializá-los deve ser a constante busca do pesquisador da alimentação. 
Entre pitadas, salpicadas e polvilhadas, realizaram-se reflexões para uma abordagem alimentar crítica na perspectiva dos conceitos de sociedade, cultura, modernidade e fronteiras. Espera-se, com este texto, fomentar maiores discussões sobre o fenômeno social da alimentação.

\section{Colaboradores}

Stefanutti P trabalhou em todas as etapas, desde a concepção do estudo até a revisão da versão final do artigo. Klauck S participou com indicação de bibliografia, discussões e interpretações, assim como da redação do artigo. Gregory V participou com indicação de bibliografia, discussões e revisão do artigo.

Conflito de interesses: Os autores declaram não haver conflitos de interesses.

\section{Referências}

1. Flusser V. Pós-história: vinte instantâneos e um modo de usar. São Paulo: Duas Cidades; 1983.

2. Giddens A. Capitalismo e moderna teoria social. Barcarena: Editorial Presença; 2005.

3. Geertz G. A interpretação das culturas. Rio de Janeiro: LTC; 1989.

4. Damatta R. O que faz o Brasil, Brasil?. Rio de Janeiro: Rocco; 1986.

5. Fischler C. El (h)omnívoro: el gusto, la cocina y el cuerpo. Barcelona: Anagrama; 1995.

6. Stefanutti P. Do couvert ao café: pescadores, memórias e comidas. [dissertação]. [Foz do Iguaçu]: Universidade Estadual do Oeste do Paraná. Centro de Educação, Letras e Saúde; 2015.

7. Pollak M. Memória, esquecimento, silêncio. Estudos Históricos. 1989; 2(3):3-15.

8. Ginzburg C. Mitos, emblemas, sinais: morfologia e história. São Paulo: Companhia das Letras; 1989.

9. Ortiz R. Mundialização e cultura. São Paulo: Brasiliense; 2003.

10. Contreras J, Gracia M. Alimentação, sociedade e cultura. Rio de Janeiro: Editora Fiocruz; 2011.

11. Montanari M. Comida como cultura. São Paulo: Editora Senac; 2008.

12. Cascudo LC. História da alimentação no Brasil. 3 ed. São Paulo: Global; 2004.

13. International Potato Center. Potato [Internet]. [acesso em: 26 abr. 2017]. Disponível em: http:// cipotato.org/potato/

14. Norbert E. O processo civilizador: 1. Uma história dos costumes. Rio de Janeiro: Jorge Zahar; 1994.

15. Albuquerque JLC. Fronteiras: entre os caminhos da observação e os labirintos da interpretação. In: Colognese AS, Cardin EG, organizadores. As ciências sociais nas fronteiras: teorias e metodologias de pesquisa. Cascavel, PR: JB; 2014. p. 61-80. 
16. Schallenberger E. Ruptura histórica e (des)continuidades culturais na fronteira: os desafios do pesquisador. In: Colognese AS, Cardin EG, organizadores. As ciências sociais nas fronteiras: teorias e metodologias de pesquisa. Cascavel, PR: JB, 2014. p. 215-238.

17. Woodward K. Identidade e diferença: uma introdução teórica e conceitual. In: Silva TT, organizador. Identidade e diferença: a perspectiva dos estudos culturais. Petrópolis, RJ: Vozes; 2000.

Recebido: 08 de novembro, 2017

Revisado: 05 de maio, 2018

Aceito: 26 de julho, 2018 
